\title{
Willingness to receive intravenous buprenorphine treatment in opioid- dependent people refractory to oral opioid maintenance treatment: results from a community-based survey in France
}

Perrine Roux ${ }^{1,2^{*}}$ D , Daniela Rojas Castro ${ }^{3,4}$, Khadim Ndiaye ${ }^{1,2}$, Laélia Briand Madrid ${ }^{1,2}$, Virginie Laporte ${ }^{3}$, Marion Mora ${ }^{1,2}$, Gwenaelle Maradan ${ }^{1,2}$, Stéphane Morel ${ }^{3}$, Bruno Spire ${ }^{1,2}$ and Patrizia Carrieri ${ }^{1,2}$

\begin{abstract}
Background: Injectable opioids are an interesting option for people who inject drugs (PWID) that do not respond to oral Opioid Maintenance Treatment (OMT). To date, intravenous (IV) buprenorphine - a safer drug than full-opioid agonists in terms of overdose risk - has never been tested in a clinical trial on opioid dependence. We designed a survey to better understand the profile of PWID eligible for IV buprenorphine, and their willingness to receive it.

Methods: This cross-sectional community-based national survey was conducted through face-to-face interviews (in lowthreshold and addiction care services) and online questionnaires (on https://psychoactif.org and other websites). Among the 557 participants, we selected those who were eligible for IV buprenorphine treatment (history of oral OMT, regular opioid injection) ( $n=371$ ). We used regression models to study factors associated with willingness to receive IV buprenorphine treatment among those with data on willingness $(n=353)$. In those who were willing $(n=294)$, we subsequently studied their willingness to receive daily supervised IV buprenorphine treatment.

Results: Among the selected 353 participants, 59\% mainly injected buprenorphine, 15\% heroin, 16\% morphine sulfate and $10 \%$ other opioids. Eighty-three percent of the sample reported willingness to receive IV buprenorphine treatment. Factors associated with willingness were: more than 5 injection-related complications, regular buprenorphine injection, no lifetime overdose, and completion of the questionnaire online. Factors associated with unwillingness to receive daily supervised treatment were younger age (OR[IC95\%] $=1.04[1.01 ; 1.07])$ and stable housing (OR[IC95\%] $=0.61[0.37 ; 1.01])$ while regular heroin injectors were more willing to receive daily supervision (OR[IC95\%]=2.94 [1.42; 6.10]).
\end{abstract}

Conclusions: PWID were very willing to receive intravenous buprenorphine as a treatment, especially those with multiple injection-related complications. In addition, our findings show that IV buprenorphine may be less acceptable to PWID who inject morphine sulfate. Young PWID and those with stable housing were unwilling to receive IV buprenorphine if daily supervision were required. This preliminary study provides useful information for the development of a clinical trial on IV buprenorphine treatment.

Keywords: Willingness, Intravenous buprenorphine, Opioid dependence, Cutaneous complications, Community-based research

\footnotetext{
* Correspondence: perrine.roux@inserm.fr

${ }^{1}$ Aix Marseille Univ, INSERM, IRD, SESSTIM, Sciences Economiques and

Sociales de la Santé and Traitement de l'Information Médicale, Marseille,

France

${ }^{2}$ ORS PACA, Observatoire régional de la santé Provence-Alpes-Côte d'Azur,

Marseille, France

Full list of author information is available at the end of the article
} 


\section{Strengths and limitations of this study}

- To our knowledge, this is the first study to explore the willingness for intravenous buprenorphine treatment among people who inject drugs (PWID).

- We used a community-based approach.

- This study aimed to identify the most appropriate conditions for the introduction of the first injectable treatment for opioid dependence in France.

- Our findings help provide a greater understanding of PWID sub-groups would not be interested in IV buprenorphine treatment and of the relevance of take-home doses for specific sub-groups.

- The study sample is not representative of all PWID, only those who frequently visit harm reduction services and associated websites.

\section{Background}

Despite access to Opioid Maintenance Treatment (oral methadone and buprenorphine) in France, some people who use drugs (PWUD) continue to inject opioids, mainly dissolved buprenorphine tablets [1]. While access to buprenorphine in primary care as an oral opioid maintenance treatment (OMT) has been possible since 1996 thanks to its safety profile $[2,3]$, methadone induction in France is possible only in specialized care [4]. However, due to its easier accessibility and its comparable efficacy as regards opioid dependence [5], oral buprenorphine is diverted more than methadone through "doctor shopping" practices [6]. Moreover, western countries are facing the growing problem of diversion of prescription opioids (PO) through injection [7]. In France, this is especially true for oral buprenorphine [1]. Morphine sulfate, another prescription opioid (PO) used as an analgesic for persistent pain, is also widely prescribed for opioid dependence and is also diverted by intravenous use [8].

The injection of illicit opioids or PO in a non-medical context has dramatic health consequences for people who inject drugs (PWID). The first is that it can promote the transmission of HIV and Hepatitis [9]. The second is that it can create complications at the injection site [10]. Some studies have reported local lesions associated with the injection of buprenorphine tablets [11] and morphine sulfate capsules [12], but also cardiovascular and pulmonary complications arising from the injection of drugs intended for oral use [13-15]. The use of prescribed injectable treatments for opioid dependence could help promote education about safer injection and reduce risks [16].

In recent years, several studies have tested injectable opioid treatment based on diacetylmorphine - also described as heroin-assisted treatment or medical heroin and highlighted its effectiveness in terms of increased retention and reduced illicit opioid use [17-20]. Heroinassisted treatment exists in several countries, including
Switzerland, Germany, the Netherlands and Denmark, and has shown positive long-term outcomes such as reduced illicit drug use and criminality, as well as an improved physical, mental and social health [21]. However, this treatment necessitates traveling up to three times a day to the clinic to receive doses [22]. Heroin-assisted treatment is not available in France. As a first step in deciding on whether to implement heroin-assisted treatment, and how to best meet the needs of people who inject buprenorphine illegally, the Inserm collective expert report on Harm Reduction in 2010 [23] suggested evaluating the feasibility of prescribing IV buprenorphine as a treatment.

Buprenorphine is associated with a lower risk of overdose than other full agonist analgesics (diacetylmorphine, morphine sulfate and methadone) [3] as it causes limited respiratory depression, and has a ceiling effect due to its partial agonist profile [24]. This safer profile may translate into less restrictive medical follow-up for stabilized patients. Following up on the report from 2010 and given the current French situation, in 2015 the French medical community and some of the country's national authorities opened the way for the implementation of a clinical trial to evaluate the effectiveness of IV buprenorphine for opioid-dependent individuals refractory to oral OMT. It must be underlined that IV buprenorphine does not exist as a treatment for opioiddependent individuals anywhere in the world. In order to inform decisions regarding the protocol for this clinical trial, it was decided to first implement a community-based survey among frequent opioid injectors already exposed to an oral treatment, to identify their willingness to receive IV buprenorphine treatment.

\section{Methods \\ Study design}

This cross-sectional community-based survey was conducted in collaboration with the association AIDES and with the support of other associations (Psychoactif, Fédération Addiction, ASUD, Médecins du Monde) in contact with PWID. It was implemented between May and August 2015 throughout France and enrolled PWID in two different ways: a) face-to-face questionnaires proposed in different sites (low-threshold services (needle exchange programs, NGOs) and addiction care services) and $\mathrm{b}$ ) online questionnaires via the community website Psychoactif.org and via an online link provided to PWID when visiting addiction care services). As the main sites of recruitment were low-threshold services, which principally attract PWID with a low socioeconomic status, to ensure representativeness, it was important to also recruit PWID with a higher status online through Psychoactif.org. As the survey was community-based, PWID and people working with them were involved in 
its preparation, especially with regard to improving the relevance and wording of the associated questionnaire items. The study received authorization from the national French Data Protection Authority (CNIL).

\section{Study sample}

Participation was proposed to all PWID either directly by field stakeholders or through an advertisement on the Psychoactif website for drug users. The survey aimed to target frequent injectors already exposed to OMT. Of the total 557 participants who completed the questionnaire, we excluded those who had no lifetime history of OMT $(n=32)$. We also excluded people who injected opioids fewer than 4 times a week $(n=154)$ (Fig. 1). This cut-off is in line with studies on injectable heroin whose criteria for study inclusion ranged from opioid use in $\geq 50 \%$ of days during the preceding 3 months [18] to daily opioid use [19].

\section{Questionnaire and variables}

A short 31-item questionnaire was administered either online or face-to-face by a community front-line worker. It included 3 sections: 1) socio-demographic characteristics, behavioral and health data (type of OMT, HIV/HCV/ HBV status, etc.); 2) drug use practices (type, dose, frequency, polydrug use, etc.), reasons for using drugs by injection, perceived complications; 3) willingness to receive IV buprenorphine treatment, preferences for the type of injecting system (simple vial with syringe or prefilled syringe) and doses.
The variable "opioid most injected" was built using the number of days per month and identifying the most frequently injected opioid.

Reasons for using drugs by injection were classified into 3 categories as follows: "to avoid withdrawal or to feel capable of daily functioning", "to get high", and "for the pleasure of the act of injecting".

Willingness was assessed using two questions: 1) Are you willing to receive IV Buprenorphine (yes, no)? 2) How would you rate your willingness to receive IV Buprenorphine on a scale from 0 to 10 ? We used the first question to classify willingness (Yes or No). If the participant answered "No" or "Don't know" to the first question but had a score $\geq 1$ for the second question, willingness was reclassified as positive. If the participant answered "Yes" or "Don't know" to the first question but had a score $=0$ for the second question, then willingness was reclassified as negative.

\section{Statistical analyses}

\section{Description of participants eligible for IV buprenorphine}

We compared participants included in the analyses with those excluded using a Chi-square or exact Fisher test for discrete variables, and Student's $\mathrm{T}$ test for continuous variables. We also compared participants who completed the questionnaire online with those who answered it face-to-face.

\section{Factors associated with willingness to receive IV buprenorphine treatment}

We first studied factors associated with willingness to receive IV buprenorphine treatment in all opioid-injecting

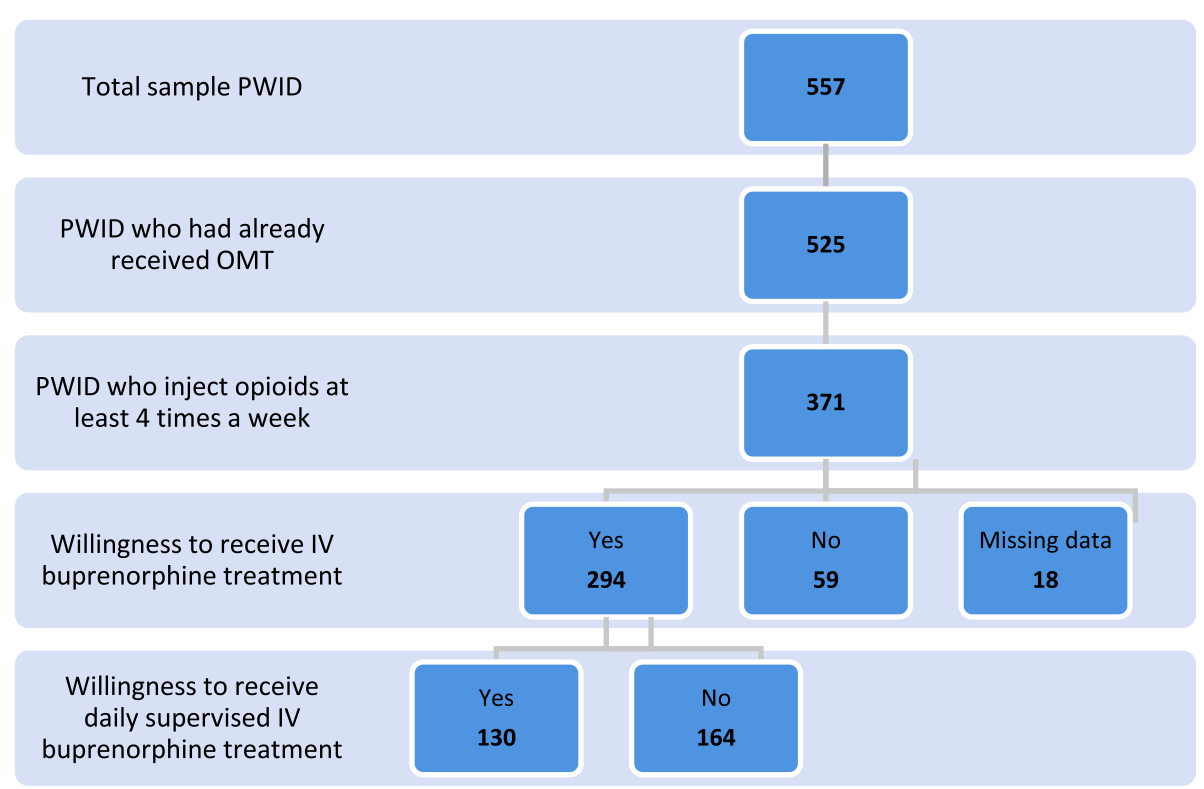

Fig. 1 Flow chart - PrebupIV study $(n=557)$. OMT = Opioid Maintenance Treatment 
users of the study sample with available data $(n=353)$. For this sub-group, we then studied factors associated with willingness to receive daily supervised IV buprenorphine treatment $(n=294)$. For both analyses, we used a logistic regression model. We used a threshold of $P$-value $<0.20$ in the univariate analyses to identify variables eligible to enter the multiple logistic regression model. A backward procedure was then used to select the explanatory variables for the final model, with a $P$-value $<0.05$.

\section{Results}

\section{Descriptive analysis of the study sample $(n=371)$}

The only differences found between participants excluded from the analyses and the study sample $(n=371)$ were that the former were more likely to have completed the questionnaire online and to be unemployed.

The comparison between participants who completed questionnaires online $(n=95)$ with those who answered it face-to-face $(n=176)$ showed that the former were more likely to be women, younger, employed, were less likely to use cocaine and alcohol, and were less likely to report being HCV positive (Table 1). Among the 371 included participants, $20 \%$ were female and median[IQR] age was $33[28 ; 40]$ years. More than half $(58 \%)$ had stable housing and $32 \%$ were employed. With respect to opioid use, $58 \%$ mainly injected oral buprenorphine, 15\% heroin, $17 \%$ oral morphine sulfate and $10 \%$ other prescription opiates (methadone, oxycodone, codeine and others). With respect to non-opioid drug use, 50\% reported using cocaine, $32 \%$ benzodiazepines and $43 \%$ alcohol. When asked about the main reason why they injected drugs, $24 \%$ answered to get high, $58 \%$ to avoid withdrawal symptoms or to feel capable of daily functioning, and $18 \%$ for the pleasure of the act of injecting. In morphine sulfate injectors, $42 \%$ reported that their main reason for injection was to get high, $50 \%$ to avoid withdrawal and $8 \%$ the pleasure of injecting. Only $15 \%$ of buprenorphine injectors reported that getting high was their main reason for injecting, $61 \%$ reporting that it was to avoid withdrawal, and $23 \%$ for the pleasure of the act. In heroin injectors, $31 \%$ answered to get high, $63 \%$ to avoid withdrawal symptoms, and $6 \%$ for the pleasure of the act of injecting, while for other opioid injectors, these values were, respectively, $45 \%, 38 \%$ and $17 \%$.

Among buprenorphine injectors, the median[IQR] dose of injected oral buprenorphine was $12[8-16] \mathrm{mg}$, and the median[IQR] number of buprenorphine injections was 3 [2-4] per day (Table 1).

With respect to complications associated with drug injection, the 5 most frequent complications were hand swelling (17\%), vein obstruction (16\%), rolling veins (16\%), cotton fever (15\%) and cutaneous abscesses (14\%). Fifteen percent of participants reported more than 5 complications (from 0 to 10). A history of overdose and incarceration were reported by $23 \%$ and $40 \%$ of PWID, respectively. Eighty percent of the study sample reported they were currently on OMT and 31\% reported being HCV positive. Seventy-one percent were on buprenorphine, $10 \%$ on methadone, $13 \%$ on morphine sulfate, and $6 \%$ reported receiving more than one OMT during the previous month. Finally, a high proportion $(83 \%)$ of the sample answered that they would be willing to use IV buprenorphine as a treatment.. When asked about their preference regarding the type of injecting system, $62 \%$ stated they would prefer a simple vial, and $25 \%$ a pre-filled syringe, while $13 \%$ said they did not know.

\section{Factors associated with willingness to receive IV buprenorphine treatment}

Among those who had data on willingness $(n=353)$, univariate analyses (Table 2 ) showed no difference in sociodemographic factors between those willing and those not willing to receive intravenous buprenorphine as a treatment for dependence. With respect to drug use practices, results showed that buprenorphine injecting drug users were more likely to accept buprenorphine as an injectable treatment than morphine sulfate (OR [95\% CI]: 0.07 [0.03; 0.16]; $p<0,001$ ) or heroin injecting drug users (OR [95\% $\mathrm{CI}]: 0.13[0.05 ; 0.32] ; p<0,001)$. The variable "reason for injecting drugs" was eligible for the multiple logistic regression analysis, since participants who reported injecting drugs for the pleasure of the act (OR [95\% CI]: 5.11 [1.80; $14.49], p=0.002)$ and to avoid withdrawal (OR [95\% CI]: 6.10 [2.89; 12.89]; $p<0.001)$ were more likely to accept IV buprenorphine treatment. Those who reported alcohol consumption were less willing to receive injectable treatment (OR [95\% CI]: 0.46 [0.26; 0.81]; $p=0.007$ ). Furthermore, reporting more than 5 complications related to drug injection was associated with greater willingness to receive the treatment. A history of overdose during one's lifetime was associated with lower willingness. Finally, participants on opioid maintenance treatment (OMT) were more likely to accept IV buprenorphine treatment than those not on OMT.

After adjustment for how the questionnaire was completed (i.e., online versus face-to-face), multiple logistic regression analysis (Table 2) showed that those who regularly injected buprenorphine (heroin: AOR [95\% CI]: 0.11 [0.04; 0.29], $p<0.001$; prescription opiates ${ }^{1}$ : AOR [95\% $\mathrm{CI}]: 0.06$ [0.03; 0.14], $p<0.001)$ and those who reported a large number of associated complications ( $>5$ ) (AOR [95\% CI]: 3.30 [1.13; 9.61], $p=0.029)$ were more likely to be willing to receive IV buprenorphine treatment for opioid dependence, while those who had a history of overdose (AOR [95\% CI]: 0.28 [0.14; 0.59], $p=0.001$ ) were less likely. 
Table 1 Descriptive analysis of the eligible participants for injectable treatment in the prebuplV survey ( $n=371$ participants)

\begin{tabular}{|c|c|c|c|c|}
\hline & $\begin{array}{l}\text { Questionnaire online } \\
(n=95)\end{array}$ & $\begin{array}{l}\text { Questionnaire face-to-face } \\
(n=276)\end{array}$ & $P$-value & $\begin{array}{l}\text { Total } \\
(n=371)\end{array}$ \\
\hline Gender & & & 0.03 & \\
\hline male & $66(72)$ & $226(82)$ & & $292(80)$ \\
\hline female & $26(28)$ & $48(18)$ & & $74(20)$ \\
\hline \multicolumn{5}{|l|}{ Age - years $^{\mathrm{a}}$} \\
\hline Median [IQR] & $31[24 ; 40]$ & $34[29 ; 40]$ & 0.02 & $33[28 ; 40]$ \\
\hline Stable housing & & & 0.61 & \\
\hline No & $37(39)$ & $116(42)$ & & $153(42)$ \\
\hline Yes & $57(61)$ & $158(58)$ & & $215(58)$ \\
\hline Employment & & & 0.02 & \\
\hline No & $53(58)$ & $196(72)$ & & $249(68)$ \\
\hline Yes & $38(42)$ & $77(28)$ & & $115(32)$ \\
\hline Opioid most injected ${ }^{\mathrm{b}}$ & & & 0.17 & \\
\hline Morphine sulfate & $14(15)$ & $50(18)$ & & $64(17)$ \\
\hline Heroin & $21(22)$ & $35(13)$ & & $56(15)$ \\
\hline Buprenorphine $^{c}$ & $52(55)$ & $164(59)$ & & $216(58)$ \\
\hline Other prescription opiates $^{d}$ & $8(8)$ & $27(10)$ & & $35(10)$ \\
\hline Main reason for injecting & & & 0.27 & \\
\hline To get "high" & $19(20)$ & $53(27)$ & & $72(24)$ \\
\hline $\begin{array}{l}\text { To avoid withdrawal or to } \\
\text { feel good enough for daily } \\
\text { functioning }\end{array}$ & $60(65)$ & $109(55)$ & & $169(58)$ \\
\hline Pleasure of the act & $14(15)$ & $38(19)$ & & $52(18)$ \\
\hline Cocaine $u s e ~^{b}$ & & & $<0.001$ & \\
\hline No & $67(72)$ & $116(42)$ & & $183(50)$ \\
\hline Yes & $26(28)$ & $157(58)$ & & $183(50)$ \\
\hline Benzodiazepine use $\mathrm{e}^{\mathrm{b}}$ & & & 0.223 & \\
\hline No & $68(73)$ & $181(66)$ & & $249(68)$ \\
\hline Yes & $25(27)$ & $92(34)$ & & $117(32)$ \\
\hline Alcohol consumption ${ }^{\mathrm{b}}$ & & & $<0.001$ & \\
\hline No & $71(75)$ & $141(51)$ & & $212(57)$ \\
\hline Yes & $24(25)$ & $135(49)$ & & $159(43)$ \\
\hline Injection-related complications & & & 0.84 & \\
\hline$\leq 5$ complications & $81(85)$ & $233(84)$ & & $314(85)$ \\
\hline$>5$ complications & $14(15)$ & $43(16)$ & & $57(15)$ \\
\hline History of overdose & & & 0.89 & \\
\hline No & $74(78)$ & $213(77)$ & & $287(77)$ \\
\hline Yes & $21(22)$ & $63(23)$ & & $84(23)$ \\
\hline Currently on OMT & & & 0.43 & \\
\hline No & $20(21)$ & $53(19)$ & & $73(20)$ \\
\hline Yes & $75(79)$ & $223(81)$ & & $298(80)$ \\
\hline Self-reported HCV status & & & 0.020 & \\
\hline No & $70(79)$ & $170(65)$ & & $240(69)$ \\
\hline Yes & $19(21)$ & 90 (35) & & 109 (31) \\
\hline
\end{tabular}

IQR Interquartile range, OMT Opioid Maintenance Treatment

ain years;

bduring the previous 12 months;

camong buprenorphine injectors: median [IQR] amounts (milligrams) injected per day $=12$ [8-16] and median [IQR] numbers of injection per day $=3$ [2-4]

${ }^{d}$ methadone, oxycodone, codeine and others 
Table 2 Factors independently associated with willingness to receive intravenous buprenorphine treatment in the study sample; univariate and multiple logistic regression analyses with OR estimates based on logistic regression analyses ( $n=353$ participants)

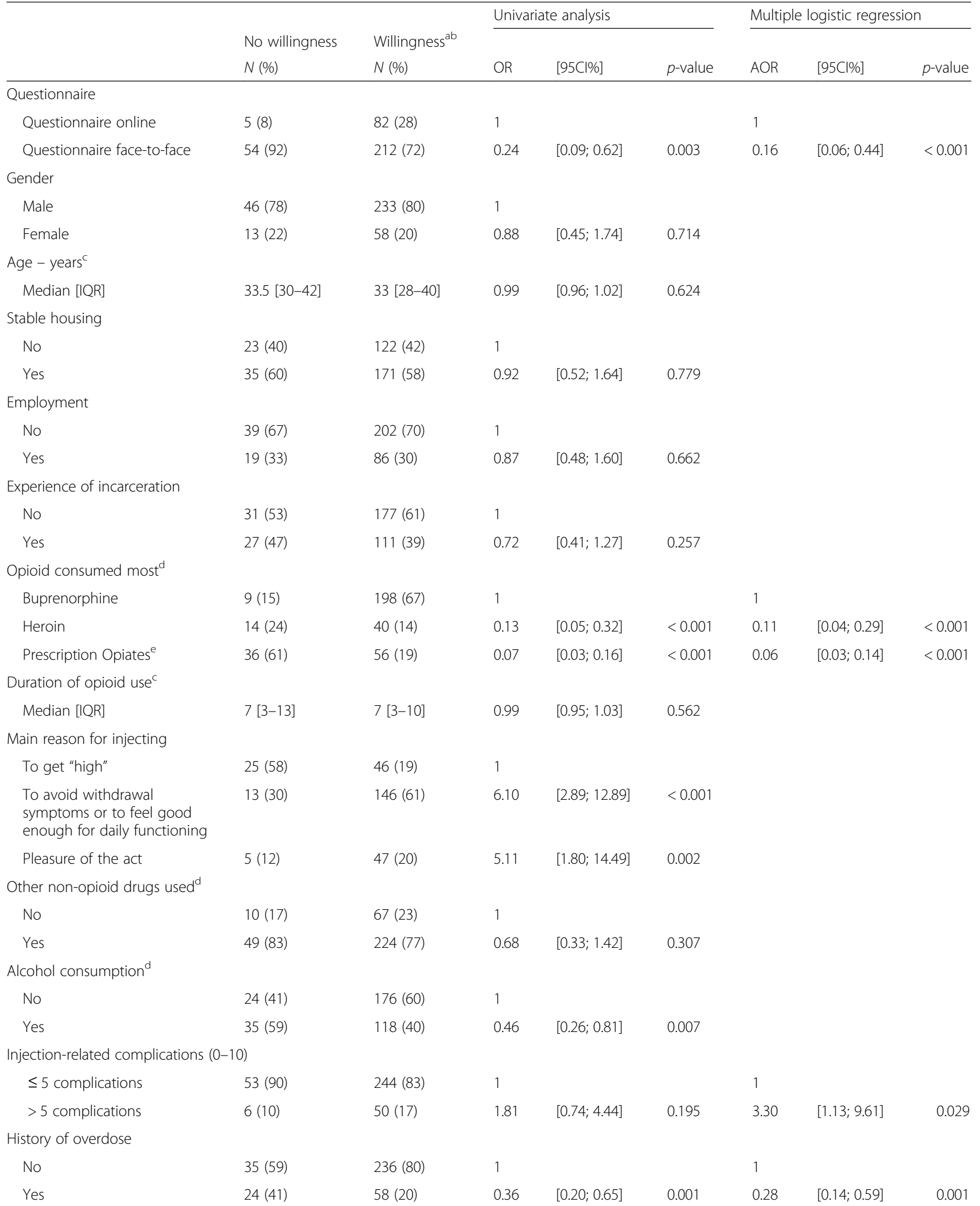


Table 2 Factors independently associated with willingness to receive intravenous buprenorphine treatment in the study sample; univariate and multiple logistic regression analyses with OR estimates based on logistic regression analyses ( $n=353$ participants) (Continued)

\begin{tabular}{|c|c|c|c|c|c|c|c|c|}
\hline & \multirow{2}{*}{$\begin{array}{l}\text { No willingness } \\
N(\%)\end{array}$} & \multirow{2}{*}{$\begin{array}{l}\text { Willingness }{ }^{\mathrm{ab}} \\
N(\%)\end{array}$} & \multicolumn{3}{|c|}{ Univariate analysis } & \multicolumn{3}{|c|}{ Multiple logistic regression } \\
\hline & & & OR & [95Cl\%] & $p$-value & AOR & [95Cl\%] & $p$-value \\
\hline \multicolumn{9}{|c|}{ Currently on OMT } \\
\hline No & $19(32)$ & $49(17)$ & 1 & & & & & \\
\hline Yes & $40(68)$ & $245(83)$ & 2.38 & {$[1.27 ; 4.44]$} & 0.007 & & & \\
\hline \multicolumn{9}{|c|}{ Self-reported HCV status } \\
\hline No & $35(64)$ & $192(70)$ & 1 & & & & & \\
\hline Yes & $20(36)$ & $84(30)$ & 0.77 & {$[0.42 ; 1.40]$} & 0.388 & & & \\
\hline
\end{tabular}

$O R$ Odds ratio, $\mathrm{Cl}$ Confidence interval

${ }^{a}$ Number of participants willing to receive IV buprenorphine $=294(83 \%)$

${ }^{b}$ Preference regarding the type of injecting system: simple vial $=62 \%$, pre-filled syringe $=25 \%$, do not know $=13 \%$

in years;

${ }^{d}$ during the previous 12 months;

emorphine sulfate, methadone, oxycodone, codeine and others

\section{Factors associated with willingness to receive daily supervision of IV buprenorphine treatment}

Among those who were willing to receive IV buprenorphine treatment $(n=294)$, those who rejected the possibility of daily supervision were more often younger (AOR [95\% CI]: $1.04[1.01 ; 1.07], p=0.014$ ) and had stable housing (AOR [95\% $\mathrm{CI}]$ : 0.61 [0.37; 1.01], $p=0.053$ ). On the contrary, heroin injectors (AOR [95\% $\mathrm{CI}]: 2.94[1.42 ; 6.10], p=0.004)$ were more willing to receive daily supervision (Table 3 ).

\section{Discussion}

To our knowledge, this is the first study to explore drug users' willingness to receive a novel injectable treatment for opioid dependence: intravenous buprenorphine. The results of this preliminary community-based survey clearly show that the level of willingness is high and provide a strong argument for the development of intravenous buprenorphine treatment. Not all the injecting opioid users who participated stated they would engage in this treatment however. Specifically, buprenorphine injectors indicated they would be more willing to participate than morphine sulfate injectors and heroin injectors. This difference between buprenorphine and heroin or morphine sulfate injectors is not surprising, as the effect and consequences of each substance are very different [25], as some PWUD report searching for a rewarding effect with morphine sulfate use [26]. This is corroborated by our results which show that $42 \%$ of morphine sulfate injectors wanted to get "high" compared with only $15 \%$ of buprenorphine users.

Our findings show that $23 \%$ of buprenorphine injectors did so for the pleasure of the act, while only $8 \%$ of morphine sulfate injectors gave this reason. Heroin users were also less willing to receive IV buprenorphine than buprenorphine users, but the difference was less marked than for morphine sulfate users.

Another interesting result is that individuals with a greater number of complications $(>5)$ were more likely to accept treatment with intravenous buprenorphine. It has been shown that almost half of PWID hospitalizations are due to cutaneous injection-related infections [27].

In addition, PWID with a history of overdose were less likely to accept IV buprenorphine. A recent study on PWID in a Canadian setting showed that the risk of overdose is higher in those who use both heroin and prescription opioids than in exclusive PO injectors [7]. Individuals with a history of overdose are more likely to have used full agonists more frequently (and reduced use of buprenorphine) and may not be willing to exclusively use injectable buprenorphine or to engage in related care. A history of overdose may be a proxy of longer history opioid use and dependence and difficult socioeconomic context (social vulnerability, prison experience, etc). Engaging these patients in care remains a challenge, but other tools like safer injecting facilities $[28,29]$ or supervised heroin programs can be a first entry point [21]. Finally, those who completed the questionnaire online were more willing to receive IV buprenorphine treatment. This may be because it was less comfortable for those who answered the questionnaire face-to-face to admit that they needed intravenous treatment [30].

Our findings also show also that not all those willing to receive IV buprenorphine would accept daily supervised injection in a medical center. More specifically, those less willing to receive daily supervision were more often younger and had stable housing. This highlights the importance of take-home doses for stabilized patients. 
Table 3 Factors independently associated with willingness to receive daily supervised buprenorphine injection at the medical center; univariate and multiple logistic regression analyses with OR estimates based on logistic regression analyses ( $n=294$ participants)

\begin{tabular}{|c|c|c|c|c|c|c|c|c|}
\hline & \multirow{3}{*}{$\begin{array}{l}\text { No willingness } \\
N(\%)\end{array}$} & \multirow{3}{*}{$\begin{array}{l}\text { Willingness }^{a} \\
N(\%)\end{array}$} & \multicolumn{3}{|c|}{$\underline{\text { Univariate analysis }}$} & \multicolumn{3}{|c|}{ Multiple logistic regression analysis } \\
\hline & & & & & & & & \\
\hline & & & OR & [95Cl\%] & $p$-value & AOR & [95Cl\%] & $p$-value \\
\hline \multicolumn{9}{|l|}{ Questionnaire } \\
\hline Questionnaire online & $50(30)$ & $32(25)$ & 1 & & & & & \\
\hline Questionnaire face-to-face & $114(70)$ & $98(75)$ & 1.34 & {$[0.80 ; 2.26]$} & 0.266 & & & \\
\hline \multicolumn{9}{|l|}{ Gender } \\
\hline Male & $125(77)$ & $108(84)$ & 1 & & & & & \\
\hline Female & $37(23)$ & $21(16)$ & 0.66 & {$[0.36 ; 1.19]$} & 0.166 & & & \\
\hline \multicolumn{9}{|l|}{ Age - years $^{\mathrm{b}}$} \\
\hline Median [IQR] & $32[27-38]$ & $34[28-41]$ & 1.02 & {$[1.00 ; 1.05]$} & 0.087 & 1.04 & {$[1.01 ; 1.07]$} & 0.014 \\
\hline \multicolumn{9}{|l|}{ Stable housing } \\
\hline No & $61(37)$ & $61(47)$ & 1 & & & 1 & & \\
\hline Yes & $103(63)$ & $68(53)$ & 0.66 & {$[0.41 ; 1.05]$} & 0.083 & 0.61 & {$[0.37 ; 1.01]$} & 0.053 \\
\hline \multicolumn{9}{|l|}{ Employment } \\
\hline No & $115(71)$ & $87(69)$ & 1 & & & & & \\
\hline Yes & $47(29)$ & $39(30)$ & 1.10 & {$[0.66 ; 1.82]$} & 0.721 & & & \\
\hline \multicolumn{9}{|l|}{ Experience of incarceration } \\
\hline No & $103(64)$ & $74(58)$ & 1 & & & & & \\
\hline Yes & $58(36)$ & $53(42)$ & 1.27 & {$[0.79 ; 2.05]$} & 0.323 & & & \\
\hline \multicolumn{9}{|l|}{ Opioid most injected ${ }^{c}$} \\
\hline Buprenorphine & $121(74)$ & $77(59)$ & 1 & & & 1 & & \\
\hline Heroin & $15(9)$ & $25(19)$ & 2.62 & {$[1.30 ; 5.28]$} & 0.007 & 2.94 & {$[1.42 ; 6.10]$} & 0.004 \\
\hline Prescription opiates $^{d}$ & $28(17)$ & $28(22)$ & 1.57 & {$[0.87 ; 2.85]$} & 0.138 & 1.52 & {$[0.83 ; 2.76]$} & 0.173 \\
\hline \multicolumn{9}{|l|}{ Duration of opioid use ${ }^{b}$} \\
\hline Median [IQR] & $7[4-10]$ & $6[3-11]$ & 1.00 & {$[0.96 ; 1.04]$} & 0.963 & & & \\
\hline \multicolumn{9}{|l|}{ Main reason for injecting } \\
\hline To get "high" & $24(17)$ & $22(22)$ & 1 & & & & & \\
\hline $\begin{array}{l}\text { To avoid withdrawal } \\
\text { symptoms or to feel good } \\
\text { enough for daily functioning }\end{array}$ & $83(59)$ & $63(64)$ & 0.83 & {$[0.43 ; 1.61]$} & 0.578 & & & \\
\hline Pleasure of the act & $33(24)$ & $14(14)$ & 0.46 & {$[0.20 ; 1.08]$} & 0.076 & & & \\
\hline \multicolumn{9}{|l|}{ Other non-opioid drugs used ${ }^{c}$} \\
\hline No & $39(24)$ & $28(22)$ & 1 & & & & & \\
\hline Yes & $124(76)$ & $100(78)$ & 1.12 & {$[0.65 ; 1.95]$} & 0.680 & & & \\
\hline \multicolumn{9}{|l|}{ Alcohol consumption ${ }^{c}$} \\
\hline No & $102(62)$ & $74(57)$ & 1 & & & & & \\
\hline Yes & $62(38)$ & $56(43)$ & 1.24 & {$[0.78 ; 1.99]$} & 0.360 & & & \\
\hline \multicolumn{9}{|c|}{ Injection-related complications (0-10) } \\
\hline$\leq 5$ complications & $139(85)$ & $105(81)$ & 1 & & & & & \\
\hline$>5$ complications & $25(15)$ & $25(19)$ & 1.32 & {$[0.72 ; 2.44]$} & 0.367 & & & \\
\hline \multicolumn{9}{|l|}{ History of overdose } \\
\hline No & $139(85)$ & $97(75)$ & 1 & & & & & \\
\hline Yes & $25(15)$ & $33(25)$ & 1.89 & {$[1.06 ; 3.38]$} & 0.031 & & & \\
\hline
\end{tabular}


Table 3 Factors independently associated with willingness to receive daily supervised buprenorphine injection at the medical center; univariate and multiple logistic regression analyses with OR estimates based on logistic regression analyses ( $n=294$ participants) (Continued)

\begin{tabular}{|c|c|c|c|c|c|c|c|c|}
\hline & \multirow{2}{*}{$\begin{array}{l}\text { No willingness } \\
\text { N (\%) }\end{array}$} & \multirow{2}{*}{$\begin{array}{l}\text { Willingness }^{\mathrm{a}} \\
\mathrm{N}(\%)\end{array}$} & \multicolumn{3}{|c|}{ Univariate analysis } & \multicolumn{3}{|c|}{ Multiple logistic regression analysis } \\
\hline & & & OR & {$[95 \mathrm{Cl} \%]$} & $p$-value & $\mathrm{AOR}$ & [95Cl\%] & $p$-value \\
\hline \multicolumn{9}{|c|}{ Currently on OMT } \\
\hline No & $25(15)$ & $24(18)$ & 1 & & & & & \\
\hline Yes & $139(85)$ & $106(82)$ & 0.79 & {$[0.43 ; 1.47]$} & 0.463 & & & \\
\hline \multicolumn{9}{|c|}{ Self-reported HCV status } \\
\hline No & $106(69)$ & $86(70)$ & 1 & & & & & \\
\hline Yes & $47(31)$ & $37(30)$ & 0.97 & {$[0.58 ; 1.63]$} & 0.909 & & & \\
\hline
\end{tabular}

$O R$ Odds ratio, $\mathrm{Cl}$ Confidence interval, IOR Interquartile range, OMT Opioid maintenance treatment

${ }^{a}$ Number of participants willing to receive daily supervised IV buprenorphine $=130(44 \%)$;

$b_{\text {in years; }}$

'during the previous 12 months;

${ }^{d}$ morphine sulfate, methadone, oxycodone, codeine and others

Heroin users willing to receive IV buprenorphine treatment were more likely to accept daily supervision. This suggests that this sample (with previous experience of OMT) may constitute suitable candidates for intravenous supervised buprenorphine treatment. More generally, our results suggest the need to diversify therapeutic options for PWID and to envisage the inclusion of supervised injectable diacetylmorphine [21] for those injecting full-agonist PO.

Some limitations have to be acknowledged. First, it is known that self-reports are subject to social desirability bias. However, their reliability in drug-using populations has been demonstrated [31]. Second, not all the survey items used were from validated questionnaires. However, they were validated here by scientific knowledge and community-based stakeholders. In terms of sociodemographic profile, our study sample was similar to those in related studies except for employment, with our study reporting a higher rate $[17,18]$. In addition, the sample of PWID participating in this survey may not be representative of all PWID in France. Nevertheless, our sample comprised PWID who frequently visit harm reduction services and associated websites, and accordingly are probably more informed than others about the availability of new treatments.

The promising findings from this preliminary study regarding PWID willingness to receive injectable buprenorphine treatment for opioid dependence are also important to obtain French institutional authorization to develop the protocol for the forthcoming clinical trial. There are two main arguments that can justify the use of injectable buprenorphine as a treatment: the first is lower abuse liability of buprenorphine than full-opioid agonists [32]. The second is that injectable buprenorphine has fewer complications than injecting oral buprenorphine $[11,33]$.

\section{Conclusions}

To conclude, the present results confirm that not all injecting drug users would be interested in IV buprenorphine treatment. Some heroin injectors, those who divert oral buprenorphine, and those with multiple injection-related complications would appear to be the most suitable populations to propose this treatment to, as part of their medical follow-up. Our work opens the way for a clinical trial which will evaluate the most appropriate conditions for the introduction of the first injectable treatment for opioid dependence in France. In countries where an opioid overdose crisis exists, IV buprenorphine may be a relevant therapeutic option for PWID [34]. In countries where IV diacetylmorphine is already available [35], IV buprenorphine may be a complementary therapeutic option for those who need less supervised treatment. Indeed, the medical follow-up envisaged for IV buprenorphine prescription is less restrictive than that for existing follow-up for treatment with injectable heroin as buprenorphine has a safer profile. This fact should enable physicians to prescribe take-home doses and to recommend less supervised injection in medical centers, according to the risk profile of the individual patient.

\section{Endnotes}

${ }^{1}$ morphine sulfate, methadone, oxycodone, codeine and others

Abbreviations

AOR: Adjusted odds ratio; Cl: Confidence interval; CNIL: Commission Nationale de I'Informatique et des Libertés / French data protection authority; HBV: Hepatitis B virus; HCV: Hepatitis C virus; HIV: Human immunodeficiency virus; INSERM: Institut National de la Santé et de la Recherche Médicale; IQR: Interquartile range; IRD: Institut de Recherche pour le Développement; IV: Intravenous; OMT: Opioid maintenance treatment: OR: Odds ratio; ORS PACA: Observatoire Régionale de la Santé Provence- 
Alpes-Côte d'Azur; PO: Prescription opioid; PWID: People who inject drugs; PWUD: People who use drugs; SESSTIM: Sciences Economiques and Sociales de la Santé and Traitement de l'Information Médicale; UMR: Unité Mixte de Recherche

\section{Acknowledgments}

We thank all the members of the PrebupIV Study Group and all the stakeholders involved, especially participating centers, their staff, and in particular the study participants. Our thanks also to Jude Sweeney for the English revision and editing of our manuscript.

The PrebuplV Study Group: P.Carrieri, P.Chappard, E.Choucair, M.Debrus, R. Delacroix, M.Dematteis, V.Doré, N. Joannard, V.Laporte, M.Mora, A.Morel, S.Morel, K.Ndiaye, F.Olivet, E.Pletschinger, D.Rojas-Castro, P.Roux, B.Spire, M.Suzan, G.Maradan, F. Vorspan.

Participating centers and their staff: S.Longere (Marseille (Bus 31/32)); J.Levy (Marseille (Nouvelle Aube)); ASUD (Marseille); M.Debrus (Paris (Gaïa)); CAARUD AIDES: G.Penavayre (Pau), C.Labbe (Lille), R.Delacroix (Paris 02), T.Salaun (Rouen/Le Havre), S.Ngiema (Le Havre), D.Abouhari (Chartres), S.Le Friec (Brest), F.Crossouard (Rennes), V.Meignan (Laval), A.Celdran (La Rochesur-Yon), J.Kubath (Bayonne), N.Fleuranceau-Rodier (Limoges), L.Baptiste (Niort), Y.Charrier (Angoulême), J.Lamant (La Rochelle), S.Coulmain (Poitiers), G.Collin (Clermont-Ferrand), C.De Froment (Toulouse), S.MC.Cormack (Béziers), C.Urdiales (Nîmes), T.Pivi (Nancy), A.Herter (Metz), JL.Ferry (Thionville), M.Daoud (Epinal), E.Bauer (Besançon), P.Skamba (Mulhouse), R.Taugourdeau (Nevers), L.Bernard (Avignon), LA.Parent (Toulon), E-Y.Lemonnier (Grenoble), E.Marty (Bourg en Bresse).

\section{Funding}

This study received external funding from the Inter-ministerial Mission for Combating Drugs and Addictive Behaviors (MILDECA). The funder had no role in study design, analysis, preparation of manuscript and decision to publish.

\section{Availability of data and materials}

Additional data are available under perrine.roux@inserm.fr

\section{Individual persons data}

Not applicable

\section{Authors' contributions}

$P R, D R C, V L, M M, G M, S M$ and PC were involved in the study concept and design as well as the acquisition of data. Statistical analyses and interpretation of data were performed by LBM, KN, PR and PC. PR was principally involved in the drafting of the manuscript with the contribution of PC and BS. All the authors revised the article for important intellectual content and gave their final approval of the version to be published. They also agreed to be accountable for all aspects of the work in ensuring that questions related to the accuracy or integrity of any part of the work be appropriately investigated and resolved.

\section{Ethics approval and consent to participate}

This study was approved by the national French Authority for Data Protection (CNIL) (approval number 1812588v0-05/12/2014). All procedures performed were in accordance with the 1964 Helsinki declaration and its later amendments. All participants in the survey gave their informed consent. The authors declare no conflict of interest.

\section{Consent for publication}

Not applicable

\section{Competing interests}

The authors declare that they have no competing interests.

\section{Publisher's Note}

Springer Nature remains neutral with regard to jurisdictional claims in published maps and institutional affiliations.

\section{Author details}

${ }^{1}$ Aix Marseille Univ, INSERM, IRD, SESSTIM, Sciences Economiques and Sociales de la Santé and Traitement de I'Information Médicale, Marseille, France. ${ }^{2}$ ORS PACA, Observatoire régional de la santé Provence-Alpes-Côte
d'Azur, Marseille, France. ${ }^{3}$ AIDES, Poitiers, France. ${ }^{4}$ Groupe de Recherche en Psychologie Sociale (EA 4163), Université Lyon 2, Bron, France.

Received: 7 August 2017 Accepted: 23 October 2017

Published online: 02 November 2017

\section{References}

1. Roux P, Villes V, Blanche J, Bry D, Spire B, Feroni I, et al. Buprenorphine in primary care: risk factors for treatment injection and implications for clinical management. Drug Alcohol Depend. 2008;97(1-2):105-13. PubMed PMID: 18479840

2. Auriacombe M, Fatseas M, Dubernet J, Daulouede JP, Tignol J. French field experience with buprenorphine. Am J Addict. 2004;13(Suppl 1):S17-28. PubMed PMID: 15204673

3. Carrieri MP, Amass L, Lucas GM, Vlahov D, Wodak A, Woody GE. Buprenorphine use: the international experience. Clin Infect Dis. 2006; 43(Suppl 4):S197-215. https://doi.org/10.1086/508184. PubMed PMID: 17109307

4. Carrieri PM, Michel L, Lions C, Cohen J, Vray M, Mora M, et al. Methadone induction in primary care for opioid dependence: a pragmatic randomized trial (ANRS Methaville). PLoS One. 2014;9(11):e112328. https://doi.org/10. 1371/journal.pone.0112328. PubMed PMID: 25393311; PubMed Central PMCID: PMC4231094

5. Mattick RP, Breen C, Kimber J, Davoli M. Buprenorphine maintenance versus placebo or methadone maintenance for opioid dependence. Cochrane Database Syst Rev. 2014;2:CD002207. PubMed PMID: 24500948

6. Delorme J, Chenaf C, Kabore JL, Pereira B, Mulliez A, Tremey A, et al. Incidence of high dosage buprenorphine and methadone shopping behavior in a retrospective cohort of opioid-maintained patients in France. Drug Alcohol Depend. 2016;162:99-106. https://doi.org/10.1016/j. drugalcdep.2016.02.035. PubMed PMID: 27006272

7. Lake S, Hayashi K, Buxton J, Milloy MJ, Dong H, Wood E, et al. The effect of prescription opioid injection on the risk of non-fatal overdose among people who inject drugs. Drug Alcohol Depend. 2015;156:297-303. https:// doi.org/10.1016/j.drugalcdep.2015.09.026. PubMed PMID: 26454837; PubMed Central PMCID: PMC4633348

8. Peyriere H, Eiden C, Micallef J, Lapeyre-Mestre M, Faillie JL, Blayac JP. Slowrelease oral morphine sulfate abuse: results of the postmarketing surveillance systems for psychoactive prescription drug abuse in France. Eur Addict Res. 2013;19(5):235-44. https://doi.org/10.1159/000346179. PubMed PMID: 23428846

9. Yokell MA, Zaller ND, Green TC, Rich JD. Buprenorphine and buprenorphine/naloxone diversion, misuse, and illicit use: an international review. Curr Drug Abuse Rev. 2011;4(1):28-41. PubMed PMID: 21466501; PubMed Central PMCID: PMC3154701

10. Dwyer R, Topp L, Maher L, Power R, Hellard M, Walsh N, et al. Prevalences and correlates of non-viral injecting-related injuries and diseases in a convenience sample of Australian injecting drug users. Drug Alcohol Depend. 2009;100(1-2):9-16. https://doi.org/10.1016/j.drugalcdep.2008.08. 016. PubMed PMID: 19013725

11. Del Giudice P. Cutaneous complications of intravenous drug abuse. $\mathrm{Br} J$ Dermatol. 2004;150(1):1-10. PubMed PMID: 14746612

12. Diot C, Eiden C, Lenoir H, Chammas M, Xatart S, Leglise Y, et al. Necrotizing fasciitis related to injections of morphine (Skenan((R))) in a HIV-infected patient. Therapie. 2014;69(2):182-5. https://doi.org/10.2515/therapie/ 2013073. PubMed PMID: 24926640

13. Shlomi D, Shitrit D, Bendayan D, Sahar G, Shechtman Y, Kramer MR Successful lung transplantation for talcosis secondary to intravenous abuse of oral drug. Int J Chron Obstruct Pulmon Dis. 2008;3(2):327-30. PubMed PMID: 18686743

14. Lamb D, Roberts G. Starch and talc emboli in drug addicts' lungs. J Clin Pathol. 1972;25(10):876-81. PubMed PMID: 4566961

15. Waller BF, Brownlee WJ, Roberts WC. Self-induced pulmonary granulomatosis. A consequence of intravenous injection of drugs intended for oral use. Chest. 1980;78(1):90-4. PubMed PMID: 7471850

16. Roux P, Le Gall JM, Debrus M, Protopopescu C, Ndiaye K, Demoulin B, et al. Innovative community-based educational face-to-face intervention to reduce HIV, hepatitis C virus and other blood-borne infectious risks in difficult-to-reach people who inject drugs: results from the ANRS-AERLI intervention study. Addiction 2016;111(1):94-106. doi: https://doi.org/10.1111/add.13089. PubMed PMID: 26234629. 
17. Haasen C, Verthein U, Degkwitz P, Berger J, Krausz M, Naber D. Heroinassisted treatment for opioid dependence: randomised controlled trial. $\mathrm{Br} J$ Psychiatry. 2007;191:55-62. https://doi.org/10.1192/bjp.bp.106.026112. PubMed PMID: 17602126

18. Strang J, Metrebian N, Lintzeris N, Potts L, Carnwath T, Mayet S, et al. Supervised injectable heroin or injectable methadone versus optimised oral methadone as treatment for chronic heroin addicts in England after persistent failure in orthodox treatment (RIOTT): a randomised trial. Lancet. 2010;375(9729):1885-95. https://doi.org/10.1016/S0140-6736(10)60349-2. PubMed PMID: 20511018

19. Oviedo-Joekes E, Brissette S, Marsh DC, Lauzon P, Guh D, Anis A, et al. Diacetylmorphine versus methadone for the treatment of opioid addiction. N Engl J Med. 2009:361(8):777-86. PubMed PMID: 19692689

20. Demaret I, Quertemont E, Litran G, Magoga C, Deblire C, Dubois N, et al. Efficacy of heroin-assisted treatment in Belgium: a randomised controlled trial. Eur Addict Res. 2015;21(4):179-87. https://doi.org/10.1159/000369337. PubMed PMID: 25832522

21. Strang J, Groshkova T, Uchtenhagen A, van den Brink W, Haasen C, Schechter MT, et al. Heroin on trial: systematic review and meta-analysis of randomised trials of diamorphine-prescribing as treatment for refractory heroin addictiondagger. Br J Psychiatry. 2015;207(1):5-14. https://doi.org/10. 1192/bjp.bp.114.149195. PubMed PMID: 26135571

22. Boyd S, Murray D, SNAP, MacPherson D. Telling our stories: heroin-assisted treatment and SNAP activism in the downtown eastside of Vancouver. Harm Reduct J. 2017;14(1):27. https://doi.org/10.1186/s12954-017-0152-3. PubMed PMID: 28521781; PubMed Central PMCID: PMCPMC5437683

23. INSERM. Reducing risks of infection amongst drug users : synthesis and recommendations. National Institute for health and medical research (INSERM), 2010.

24. Kahan M, Srivastava A, Ordean A, Cirone S. Buprenorphine: new treatment of opioid addiction in primary care. Can Fam Physician. 2011;57(3):281-9. doi: 57/3/281 [pii]. Epub 16 Mar 2011. PubMed PMID: 21402963; PubMed Central PMCID: PMC3056674

25. Lofwall MR, Walsh SL. A review of buprenorphine diversion and misuse: the current evidence base and experiences from around the world. J Addict Med. 2014;8(5):315-26. https://doi.org/10.1097/ADM.0000000000000045. PubMed PMID: 25221984; PubMed Central PMCID: PMC4177012

26. Peyriere $H$, Nogue E, Eiden C, Frauger E, Charra M, Picot MC, et al. Evidence of slow-release morphine sulfate abuse and diversion: epidemiological approaches in a French administrative area. Fundam Clin Pharmacol. 2016; 30(5):466-75. https://doi.org/10.1111/fcp.12210. PubMed PMID: 27315486

27. Lloyd-Smith E, Wood E, Zhang R, Tyndall MW, Sheps S, Montaner JS, et al. Determinants of hospitalization for a cutaneous injection-related infection among injection drug users: a cohort study. BMC Public Health. 2010;10:327 PubMed PMID: 20534148

28. Wood E, Tyndall MW, Qui Z, Zhang R, Montaner JS, Kerr T. Service uptake and characteristics of injection drug users utilizing North America's first medically supervised safer injecting facility. Am J Public Health. 2006;96(5): 770-3. https://doi.org/10.2105/AJPH.2004.057828. PubMed PMID: 16571703; PubMed Central PMCID: PMC1470579

29. Potier C, Laprevote V, Dubois-Arber F, Cottencin O, Rolland B. Supervised injection services: what has been demonstrated? A systematic literature review. Drug Alcohol Depend. 2014;145:48-68. https://doi.org/10.1016/j. drugalcdep.2014.10.012. PubMed PMID: 25456324

30. Islam MM, Topp L, Conigrave KM, van Beek I, Maher L, White A, et al. The reliability of sensitive information provided by injecting drug users in a clinical setting: clinician-administered versus audio computer-assisted selfinterviewing (ACASI). AIDS Care 2012;24(12):1496-1503. doi: https://doi.org/ 10.1080/09540121.2012.663886. PubMed PMID: 22452446.

31. Darke S. Self-report among injecting drug users: a review. Drug Alcohol Depend. 1998;51(3):253-63. discussion 67-8. PubMed PMID: 9787998

32. Comer SD, Sullivan MA, Whittington RA, Vosburg SK, Kowalczyk WJ. Abuse liability of prescription opioids compared to heroin in morphinemaintained heroin abusers. Neuropsychopharmacology. 2008;33(5):1179_ 91. PubMed PMID: 17581533

33. Decocq G, Fremaux D, Smail A, Compagnon M, Andrejak M. Local complications after intravenous injection of dissolved tablets of buprenorphine. Presse Med. 1997;26(30):1433. PubMed PMID: 9404358
34. Volkow ND, Frieden TR, Hyde PS, Cha SS. Medication-assisted therapiestackling the opioid-overdose epidemic. N Engl J Med. 2014;370(22):2063-6. https://doi.org/10.1056/NEJMp1402780. PubMed PMID: 24758595

35. Blanken $P$, Hendriks VM, van Ree JM, van den Brink W. Outcome of longterm heroin-assisted treatment offered to chronic, treatment-resistant heroin addicts in the Netherlands. Addiction. 2010;105(2):300-8. PubMed PMID: 19922517

\section{Submit your next manuscript to BioMed Central and we will help you at every step:}

- We accept pre-submission inquiries

- Our selector tool helps you to find the most relevant journal

- We provide round the clock customer support

- Convenient online submission

- Thorough peer review

- Inclusion in PubMed and all major indexing services

- Maximum visibility for your research

Submit your manuscript at www.biomedcentral.com/submit 